Document downloaded from:

http://hdl.handle.net/10251/101833

This paper must be cited as:

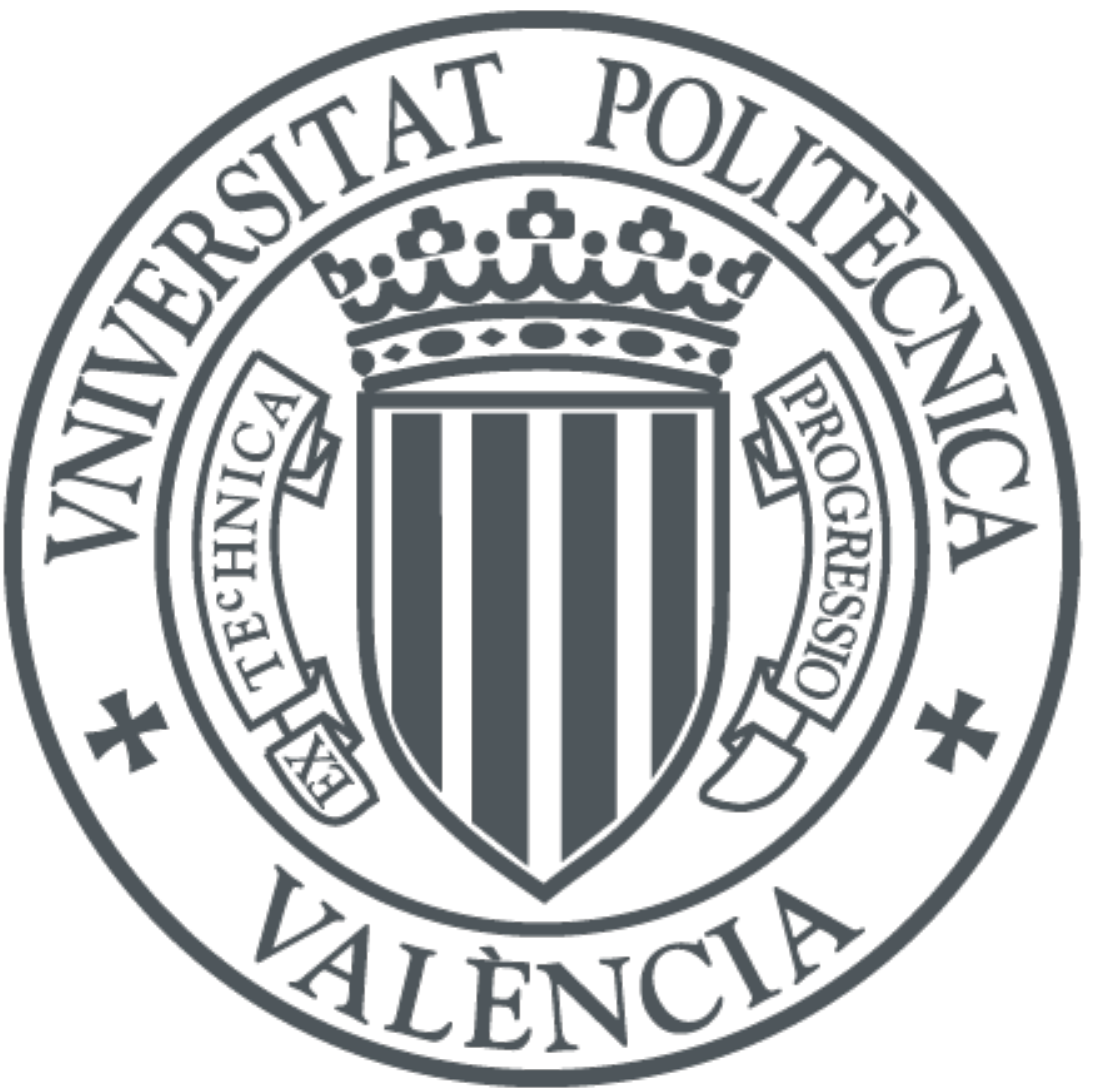

The final publication is available at

http://doi.org/10.1007/s11664-016-5215-9

Copyright Springer-Verlag

Additional Information 


\title{
SnS Thin Films Prepared by Chemical Spray Pyrolysis at Different Substrate Temperatures for Photovoltaic Applications
}

\author{
THIERNO SALL ${ }^{1}$, BERNABÉ MARÍ SOUCASE ${ }^{1,2, *}$, MIGUEL MOLLAR ${ }^{1,2}$, JUAN ANGEL SANS ${ }^{1}$ \\ ${ }^{1}$ Institut de Disseny i Fabricació, Universitat Politècnica de València, Camí de Vera s/n \\ 46022- Valencia, Spain \\ ${ }^{2}$ Departament de Física Aplicada, Universitat Politècnica de València, Camí de Vera s/n \\ 46022-Valencia, Spain \\ * Corresponding author: bmari@fis.upv.es
}

\begin{abstract}
The preparation and analysis of morphological, structural, optical, vibrational and compositional properties of tin monosulfide (SnS) thin films deposited on glass substrate by chemical spray pyrolysis (CSP) is reported herein. The growth conditions were evaluated to reduce the presence of residual phases different to the SnS orthorhombic phase. X-ray diffraction (XRD) spectra revealed the polycrystalline nature of the SnS films with orthorhombic structure and a preferential grain orientation along the (111) direction. At high substrate temperature $\left(450^{\circ} \mathrm{C}\right)$, a crystalline phase corresponding to the $\mathrm{Sn}_{2} \mathrm{~S}_{3}$ phase was observed. Raman spectroscopy confirmed the dominance of the SnS phase and the presence of an additional $\mathrm{Sn}_{2} \mathrm{~S}_{3}$ phase. Scanning electron microscopy (SEM) images reveal that the SnS film morphology depends on the substrate temperature. Between $250{ }^{\circ} \mathrm{C}$ and $350{ }^{\circ} \mathrm{C}$, SnS films were shaped as rounded grains with some cracks between them, while at substrate temperatures above $400{ }^{\circ} \mathrm{C}$ films were denser and more compact. Energy dispersive X-ray spectroscopy (EDS) analysis showed that the stoichiometry of sprayed SnS films improved with the increase of substrate temperature and atomic force microscopy (AFM) micrographs showed films well covered at $350{ }^{\circ} \mathrm{C}$ resulting in a rougher and bigger grain size. Optical and electrical measurements showed that the optical bandgap and the resistivity decreased when the substrate temperature increased, and smaller values, $1.46 \mathrm{eV}$ and $60 \Omega . \mathrm{cm}$, respectively, were attained at $450{ }^{\circ} \mathrm{C}$. These SnS thin films could be used as an absorber layer for the development of tandem solar cell devices due to their high absorbability in the visible region with optimum bandgap energy.
\end{abstract}


Keywords: SnS, Thin Films, Chemical Spray Pyrolysis, XRD, Raman Spectroscopy, AFM, SEM, Resistivity

\section{INTRODUCTION}

To obtain new photovoltaic materials to make solar cells cheaper and more efficient, tin monosulfide belonging to the IV-VI semiconductor group has gained much attention because of its suitable optoelectronic properties for photovoltaic applications. This compound has a direct bandgap near $1.3 \mathrm{eV}$ [1], which is close to optimal band gap (1.5 $\mathrm{eV})$ of solar cells and has a high absorption coefficient $\left(\alpha>10^{4} \mathrm{~cm}^{-1}\right)$ [2]. All SnS elements are abundant, cost-effective and less toxic compared to the cadmium and lead in CdS and PbS thin films, respectively. SnS also has p-type electrical conductivity and it has a theoretical high efficiency greater than 24\% [3], but still, despite many efforts, solar cells based on SnS absorbers have not achieved conversion efficiency above 1.3\% yet [4]. The low performance may be due to impurities and/or defects in the SnS layers that result from the preparation methods used. Tin monosulfide has been prepared using various techniques such as successive ionic layer adsorption and reaction (SILAR) [5], chemical bath deposition (CBD) [6], electrochemical deposition (ECD) [7], Atomic layer deposition (ALD) [8], chemical spray pyrolysis (CSP) [9], etc. Each preparation technique has its own advantages and drawbacks but the development of simple, rapid and economical methods for preparing materials with good reproducibility and with controllable deposition parameters is still a great challenge. We chose CSP for film deposition due to its inexpensive, swift, vacuumless and simple preparation [10]. In addition, it is suitable for industrial scale production.

J. Malaquias et al. prepared SnS films on glass substrate using sulfurization of metallic precursors in an $\mathrm{N}_{2}+\mathrm{S}_{2}$ atmosphere in a sulfurization temperature range from $300{ }^{\circ} \mathrm{C}$ to $520^{\circ} \mathrm{C}$. Solid mixtures of $\mathrm{SnS}, \mathrm{SnS}_{2}$ and $\mathrm{Sn}_{2} \mathrm{~S}_{3}$ were obtained for all growth conditions but optical and electrical measurements showed that the influence of secondary phases $\left(\mathrm{SnS}_{2}\right.$ and $\left.\mathrm{Sn}_{2} \mathrm{~S}_{3}\right)$ was small compared to the $\mathrm{SnS}$ phase [11]. T. H. Sajeesh et al. deposited SnS by the CSP technique at varying substrate temperatures from $300{ }^{\circ} \mathrm{C}$ to $500{ }^{\circ} \mathrm{C}$ and found a prominent peak of the $\mathrm{Sn}_{2} \mathrm{~S}_{3}$ phase at lower Ts $\left(<300{ }^{\circ} \mathrm{C}\right)$ and an $\mathrm{SnS}_{2}$ phase above Ts $\left(>400{ }^{\circ} \mathrm{C}\right)$. Otherwise, no secondary phase was detected at $350^{\circ} \mathrm{C}$ [12].

In this study, we prepared SnS thin films by the CSP technique onto simple glass substrate at different temperatures using a 1:1 ratio [S]/[Sn] . Some amount of alcohol (10\%) was added to the aqueous solvent to reduce the water surface tension. The 
crystalline structure, morphology, chemical composition, electrical and optical properties of chemical spray pyrolysis deposited SnS thin films are reported.

\section{EXPERIMENTAL DETAILS}

\section{Film preparation}

Tin monosulfide (SnS) thin films were prepared onto glass substrate from an aqueous solution containing tin (II) chloride dihydrate $\left(\mathrm{SnCl}_{2} \cdot 2 \mathrm{H}_{2} \mathrm{O}\right)$, thiourea $\left(\mathrm{CS}\left(\mathrm{NH}_{2}\right)_{2}\right)(\geq 99 \%)$ and alcohol (10\% in volume) to reduce the surface tension. The concentration of tin chloride was fixed at $0.104 \mathrm{M}$ and the $[\mathrm{S}] /[\mathrm{In}]$ ratio was 1 . The substrate temperature varied: $250^{\circ} \mathrm{C}, 300^{\circ} \mathrm{C}, 350^{\circ}, 400^{\circ} \mathrm{C}$ and $450^{\circ} \mathrm{C}$. The volume sprayed was $5 \mathrm{~mL}$, the spray rate $1.5 \mathrm{~mL} / \mathrm{min}$, the air compressed pressure $0.7 \mathrm{bar}$ and the distance between the glass substrate and nozzle was kept at $25 \mathrm{~cm}$.

Glass substrates were washed in an ultrasonic bath of acetone for $15 \mathrm{~min}$, rinsed with distilled water followed by an ethanol bath for $15 \mathrm{~min}$ and rinsed with distilled water before drying and being used for the spray process.

\section{Film Characterization}

Structural properties were characterized by means of x-ray diffraction (XRD) measurement with a Rigaku Ultima IV diffractometer at the Bragg-Brentano $(\theta-2 \theta)$ configuration and using $\mathrm{CuK} \alpha$ radiation (1.5418 $\AA$ ). Phonon vibration properties were also characterized by Raman scattering measurements performed with a LabRAM HR UV spectrometer coupled to a Peltier-cooled CCD camera with a spectral resolution of 3 $\mathrm{cm}^{-1}$ and using a $632.81 \mathrm{~nm}$ laser excitation line. The morphology was characterized using JEOL-JSM6300 scanning electron microscopy (SEM) operating at $20 \mathrm{kV}$ and the atomic force microscopy (AFM) study was carried out using a Bruker Multimode 8 AFM Nanoscope V controller. Energy dispersive X-ray spectroscopy (EDS) attached to scanning electron microscopy (SEM) was used for microanalysis. Sheet resistance was measured by the four-point probe technique and optical properties were monitored by transmittance using a Deuterium-Halogen lamp (DT-MINI-2-GS Micro Park) in coupled to a $500 \mathrm{~mm}$ Yvon-Jobin HR460 spectrophotometer using a back-thinned Si-CCD detector (Hamamatsu) optimized for the UV-VIS-Infrared range.

\section{RESULTS AND DISCUSSION}

X-Ray Diffraction (XRD) Analysis 
Figure 1a shows the XRD spectra of SnS thin films sprayed at various substrate temperatures, i.e. $250{ }^{\circ} \mathrm{C}, 300{ }^{\circ} \mathrm{C}, 350{ }^{\circ} \mathrm{C}, 400{ }^{\circ} \mathrm{C}$ and $450{ }^{\circ} \mathrm{C}$, respectively. From $250{ }^{\circ} \mathrm{C}$ to $450{ }^{\circ} \mathrm{C}$ the XRD peaks matched SnS orthorhombic phase (JCPDS\#39-0354) well. XRD peaks were located at 26.10, 30.47, 31.53, 39.05, and 44.74 degrees, corresponding to diffraction between the following crystallographic planes: (021), (101), (111), (131) and (141) respectively. The highest intensity observed for the (111) diffraction peak at $31.53^{\circ}$ is the preferential crystallographic direction for all temperatures except for films prepared at $300{ }^{\circ} \mathrm{C}$ in which the (101) peak dominates. Apart from the SnS peaks, one additional peak corresponding to the $\mathrm{Sn}_{2} \mathrm{~S}_{3}$ phase was observed in the XRD spectra for films deposited at $450^{\circ} \mathrm{C}$. This peak is due to the reevaporation of $\mathrm{SnS}$ and tin from the substrate surface as vapor [13]. $\mathrm{Sn}_{2} \mathrm{~S}_{3}$ is a compound made of $\mathrm{SnS}$ and $\mathrm{SnS}_{2}$ which means that some Sn (IV) ions are present. This may happen if part of Sn (II) dismutates into Sn (0) and Sn (IV) to produce $\mathrm{Sn}_{2} \mathrm{~S}_{3}$ as a secondary phase $[14,15]$. It is noteworthy to notice that at 400 ${ }^{\circ} \mathrm{C}$ and $450{ }^{\circ} \mathrm{C}$, the (101) peak tends to vanish and simultaneously an increase of the (111) main peak is observed. A decrease of other indexed peaks at all temperatures below 400 was also observed ${ }^{\circ} \mathrm{C}$.

Figure 1b shows a detail of the XRD pattern around the (021), (101) and (111) peaks. It is noteworthy that the (111) peak at $400{ }^{\circ} \mathrm{C}$ and $450{ }^{\circ} \mathrm{C}$ is clearly the overlap of (101) and (111) observed at substrate temperatures between $250{ }^{\circ} \mathrm{C}$ and $350{ }^{\circ} \mathrm{C}$.

The lattice plane index ( $h$ kl), interplanar distance dhkl and lattice parameters have the following relationship for orthorhombic crystal [16]:

$$
1 / d_{h k l} l^{2}=h^{2} / a^{2}+k^{2} / b^{2}+l^{2} / c^{2}
$$

Using to XRD data, we calculated the lattice parameters (a, b and c) of SnS thin films. The evaluated lattice parameters of the SnS films are listed in Table 1. Lattice parameters are in good agreement with the standard orthorhombic SnS pattern JCPDS\#39-0354.

The variation of the crystallite size with substrate temperature was investigated using the Debye-Scherrer formula from the (111) and (101) diffraction lines after deconvolution of wide (111) peaks at $400{ }^{\circ} \mathrm{C}$ and $450{ }^{\circ} \mathrm{C}$ [17]:

$$
D=K \lambda / \beta \cos \theta
$$

Where $\beta$ is the full width at half maximum (FWHM), $\lambda$ wavelength of $x$-ray whose value is $1.5418 \AA(\mathrm{CuK} \alpha), \mathrm{K}$ the Scherrer constant, which generally depends on the crystallite 
shape and is close to 1 ( $\mathrm{K}=0.9$ was used) and $\theta$ is the Bragg angle at the center of the peak. The crystallite size, D, obtained from this equation corresponds to the mean minimum dimension of a coherent diffraction domain.

Table 1 shows the crystallite sizes calculated from the Scherrer's equation for (101) and (111) diffraction peaks. The trend is the higher the temperature the smaller the crystallite size and the higher the intensity. When the temperature increases two competitive phenomena take place simultaneously: one is the increase of the crystallite size and the other one is the enlargement of the nucleation centers, which might result in an increase of the density of crystallites and then in an increase of the intensity of the diffraction peaks. In this case the second phenomenon is likely to dominate and as a result a higher density of smaller crystallites is produced when the temperature increases.

\section{Raman Spectroscopy Analysis}

Raman spectroscopy is a powerful tool to analyze the phase and structure of SnS thin films. Raman spectra were analyzed to confirm the SnS phase and to identify the presence of the other phases as well. Raman spectra of SnS thin films deposited at different substrate temperatures recorded in the range $80-350 \mathrm{~cm}^{-1}$ are shown in Figure 2. Raman spectroscopy reported modes for SnS at $94 \mathrm{~cm}^{-1}, 193 \mathrm{~cm}^{-1}, 218 \mathrm{~cm}^{-1}, 225 \mathrm{~cm}^{-1}$ assigned to $\mathrm{Ag}$, and $88 \mathrm{~cm}^{-1}, 170 \mathrm{~cm}^{-1}, 178 \mathrm{~cm}^{-1}$ belonging to $\mathrm{B} 2 \mathrm{~g}$, and for $\mathrm{Sn}_{2} \mathrm{~S}_{3}$ with a mode at $307 \mathrm{~cm}^{-1}$ [18-20]. The Raman mode at $307 \mathrm{~cm}^{-1}$ confirms the presence of the $\mathrm{Sn}_{2} \mathrm{~S}_{3}$ phase for films deposited at $450{ }^{\circ} \mathrm{C}$, which is in good agreement with the XRD spectra in Figure 1, in which the presence of the $\mathrm{Sn}_{2} \mathrm{~S}_{3}$ for films deposited at $450{ }^{\circ} \mathrm{C}$ and no Raman mode corresponding to $\mathrm{SnS}_{2}$ was observed. Otherwise, Raman spectra also confirm that the $\mathrm{SnS}$ phase is obtained in all samples prepared at different temperatures. Therefore, both Raman and x-ray diffraction results were complimentary.

\section{Scanning Electron Microscopy Analysis}

An electron beam is used to scan the surface of films in the scanning electron microscope by applying a typical acceleration voltage of $20 \mathrm{kV}$. Scanning electron microscopy characterization was carried out on all samples and representative micrographs are shown in Figure 3. SEM studies revealed that the SnS thin films deposited from $250{ }^{\circ} \mathrm{C}$ to 350 ${ }^{\circ} \mathrm{C}$ substrate temperatures were well covered and strongly adherent to the glass surface with the formation of agglomerations of small grains probably formed due to the segregation of excess tin. At $400{ }^{\circ} \mathrm{C}$ and $450{ }^{\circ} \mathrm{C} \mathrm{SnS}$ films were homogeneous, dense, 
pinholes free and more compact than films sprayed at lower temperatures. At lower temperatures (below $400^{\circ} \mathrm{C}$ ), SnS grains had a spherical shape, being almost uniform and some voids between them were observed. At higher temperatures (at $400{ }^{\circ} \mathrm{C}$ and $450{ }^{\circ} \mathrm{C}$ ), the grainy surface structure disappeared and films were denser and more compact.

\section{Atomic Force Microscopy Analysis}

The surface topography of SnS films grown at different substrate temperatures was examined by atomic force microscopy and 2D pictures scanning in an area of $3 \mu \mathrm{m} \times 3 \mu \mathrm{m}$ and a scale bar in the height of $70 \mathrm{~nm}$ are shown in Figure 4. When the substrate temperature increased from $350{ }^{\circ} \mathrm{C}$ to $450{ }^{\circ} \mathrm{C}$, the film surface roughness decreased from $24.7 \mathrm{~nm}$ to $16.6 \mathrm{~nm}$ probably due to the suppression of the segregation of tin on the surface. Films deposited at $350{ }^{\circ} \mathrm{C}$ were the roughest $(24.7 \mathrm{~nm})$ and had the largest grain size (252 nm), while films prepared at $450{ }^{\circ} \mathrm{C}$ had the lowest roughness $(16.6 \mathrm{~nm})$ and the smallest grain size $(148 \mathrm{~nm})$. Roughness and grain size for all samples are shown in Table 2. Furthermore, when the substrate temperature increased from 350 to $450{ }^{\circ} \mathrm{C}$, the void fraction over the surface decreased, resulting in a reduction of the roughness (Table 2). Therefore, the film surfaces were smoother compared to films prepared at 250 and 300 ${ }^{\circ} \mathrm{C}$. The difference between the crystallite size given by Scherrer's equation and the grain size given by AFM is due to the fact that a grain is an agglomeration of several crystallites.

Taken into account the data provided by XRD and AFM measurements, the increase of substrate temperature results in the formation of a larger number of crystallites but with smaller sizes. This effect can be related to the generation of a higher density of nucleation centers with the temperature resulting in a higher density of crystallites but with smaller sizes.

\section{Energy Dispersive X-ray Spectroscopy Measurements}

Energy dispersive x-ray spectroscopy is a powerful technique to analyze the chemical composition of the sample, being based on x-ray emitted by the atoms in the sample. The Molar ratios shown in Table 3 indicate that all films contain only sulfur and tin. The proportion of S and $\mathrm{Sn}$ in $\mathrm{SnS}$ thin films revealed that when the substrate temperature increased from $250{ }^{\circ} \mathrm{C}$ to $350{ }^{\circ} \mathrm{C}$, all the ratios indicated an excess of tin, but when the substrate temperature was $400{ }^{\circ} \mathrm{C}$ and $450{ }^{\circ} \mathrm{C}$, respectively, a drastic decrease in the amount of tin was observed, leading to S/Sn close to unity confirming the XRD results. 
Therefore, according to the EDS results the stoichiometry deviation can be attributed to the excess of tin.

\section{Electrical Measurements}

The Resistivity of the samples was obtained by the four-probe technique. Table 4 displays the thickness, sheet resistance and resistivity of all samples in relation to the substrate temperature. A decrease in the resistivity of films was observed when the substrate temperature rose from 250 to $450{ }^{\circ} \mathrm{C}$, being is correlated with the decrease of film thicknesses. The lowest thickness $(576 \mathrm{~nm})$ and resistivity $(60 \Omega \cdot \mathrm{cm})$ were obtained for films prepared at the highest temperature, $450{ }^{\circ} \mathrm{C}$.

\section{Optical Analysis}

The optical transmittance of SnS thin films deposited by CSP onto simple glass taken in the range of $500-1000 \mathrm{~nm}$ is displayed in Figure 5. We noted a low transmittance at low substrate temperature of $250{ }^{\circ} \mathrm{C}$ and an increase of the transmittance from $300{ }^{\circ} \mathrm{C}$ to $450{ }^{\circ} \mathrm{C}$ due to the decrease of thickness when the substrate temperature increased from 250 to $450{ }^{\circ} \mathrm{C}$. We also noted, particularly, that films prepared at a substrate temperature in the range of 350 to $450{ }^{\circ} \mathrm{C}$ had the same transmittance variation. For all films, the transmittance starts above $800 \mathrm{~nm}$, as characteristic for an SnS absorber layer.

The bandgap energies for SnS thin films were obtained from optical transmission data plotting $(\mathrm{Ah} v)^{2}$ versus $\mathrm{h} v$ at various temperatures, where $\mathrm{A}$ is the absorbance and $\mathrm{h} v$ is the photon energy. The calculated optical bandgap for every sample appears in the legend of Figure 6. At lower temperatures, $250{ }^{\circ} \mathrm{C}$ and $300^{\circ} \mathrm{C}$, a suitable bandgap energy between $1.70 \mathrm{eV}$ to $1.74 \mathrm{eV}$ was calculated, while at a higher substrate temperature, in the range of 350 to $450{ }^{\circ} \mathrm{C}$, the gap energy decreased from $1.50 \mathrm{eV}$ (the ideal bandgap energy) to $1.46 \mathrm{eV}$. The change in preferred film orientation from (010) to (111) planes can be correlated to the change in the optical gap energy of SnS thin films; the optical bandgap of SnS changed from 1.74 to $1.46 \mathrm{eV}$ when the substrate temperature increased from 300 to $450{ }^{\circ} \mathrm{C}$, respectively, where the parallel plane was replaced by a plane perpendicular to the surface.

\section{CONCLUSIONS}

Tin monosulfide (SnS) thin films were deposited by the CSP technique using $\mathrm{SnCl}_{2} \cdot 2 \mathrm{H}_{2} \mathrm{O}$ and $\mathrm{CS}\left(\mathrm{NH}_{2}\right)_{2}$ as precursors of tin (II) and sulfur, respectively. All films 
were polycrystalline and crystallized in the SnS orthorhombic phase, with (111) as main peak. No $\mathrm{SnS}_{2}$ Raman mode was observed, while $\mathrm{Sn}_{2} \mathrm{~S}_{3}$ modes were detected, thus confirming the XRD results. In addition, two SnS modes were observed in all samples. The SnS films showed a granular morphology between $250{ }^{\circ} \mathrm{C}$ and $350{ }^{\circ} \mathrm{C}$, while at 400 ${ }^{\circ} \mathrm{C}$ and $450^{\circ} \mathrm{C}$, films became denser and more compact. According to Energy-dispersive X-ray spectroscopy results, films with improved stoichiometry could be achieved with higher substrate temperatures, and AFM micrographs showed films with a greater roughness and relatively big grain size. The optical energy bandgap and electrical resistivity were found to decrease with the increase of the substrate temperature achieving a minimum of $1.46 \mathrm{eV}$ and $60 \Omega . \mathrm{cm}$ at $450{ }^{\circ} \mathrm{C}$, respectively.

Polycrystalline SnS films with good stoichiometry, denser and compact morphology and suitable gap energy of 1.46-1.50 eV were obtained by the CSP inexpensive technique and also using abundant elements ( $\mathrm{Sn}$ and S), making SnS to be a promising candidate to substitute the CuInS 2 absorber layer in solar cells thin films technology.

The results obtained herein emphasize that the influence of substrate temperatures on the physical and chemical properties of SnS films pyrolysised is crucial in order to produce suitable SnS films, which have to be deposited at temperatures from $350-450{ }^{\circ} \mathrm{C}$.

\section{Acknowledgments}

This work was supported by Ministerio de Economía y Competitividad (ENE201346624-C4-4-R) and Generalitat valenciana (Prometeus 2014/044). 


\section{REFERENCES}

1. N. R. Mathews, H. B. M. Anaya, M. A. Cortes-Jacome, C. Angeles-Chavez, and J. A. Toledo-Antonio, J. Electrochem. Soc. 157, H337 (2010)

2. N. Koteeswara Reddy, K. Ramesh, R. Ganesan, K. Reddy, K. R. Gunasekhar, E. Gopal, Appl. Phys. A, 83, 133 (2006)

3. J. J. Loferski, J. Appl. Phys, 27, 777 (1956)

4. K. T. R. Reddy, N. K. Reddy, and R. W. Miles, Sol. Energ. Mat. Sol. C, 90, 3041 (2006)

5. C. Gao, H. L. Shen, L. Sun, H. B. Huang, L. F. Lu, and H. Cai, Mater. Lett, 64, 2177 (2010)

6. D. Avellaneda, M. T. S. Nair, and P. K. Nair, J. Electrochem. Soc, 155, D517 (2008)

7. J. R. S. Brownson, C. Georges, and C. Levy-Clement, Chem. Mater, 19, 3080 (2007)

8. P. Sinsermsuksakul, J. Heo, W. Noh, A. S. Hock, and R. G. Gordon, Adv. Eng. Mat, 1, 1116 (2011)

9. T. Sall, M. Mollar and B. Marí, J. Mater. Sci. (2016) DOI 10.1007/s10853-016-00399.

10. K. Otto, A. Katerski, O. Volobujeva, A. Mere, and M. Krunks, Energy Procedia3, $63(2011)$

11. J. Malaquias, P.A. Fernandes, P.M.P. Salomé and A.F. da Cunha, Thin Solid Films 519, $7416(2011)$

12. T.H. Sajeesh, Anita R. Warrier, C. Sudha Kartha, K.P. Vijayakumar, Thin Solid Films 518, 4370 (2010)

13. M. Vasudeva Reddy, G. Sreedevi, Chinho Park, R.W. Miles, and K. T. Ramakrishna Reddy, Current Applied Physics, 15, 588 (2015)

14. A. Molenaar, Extended Abstracts, Vol. 84-2, The Electrochemical Society, Pennington, N.J., 634 (1984)

15. S. López, S. Granados, A. Ortiz, Semicond. Sci. Technol. 11, 433 (1996)

16. B. Cullity, Elements of X-ray diffraction, Addision-Wesley Publishing Company Inc., USA, 501 (1967)

17. G. Willeke, R. Dasbach, B. Sailer, and E. Bucher, Thin Solid Films 213, 271 (1992)

18. H. R. Chandrasekhar, R. G. Humphreys, U. Zwick and M. Cardona, Physical Review $B, 15$, Number 4, 2177 (1977)

19. S. Cheng, G. Conibeer, Thin Solid Films, 520, 837 (2011)

20. J. Malaquias, P.A. Fernandes, P.M.P. Salome, and A.F. da Cunha, Thin Solid Films, 519, 7416 (2011) 